\title{
Regioisomeric $\alpha$-hydroxy chlorohydrins from the reaction of mucochloric acid and guanosine
}

\author{
Karel D. Klika*a , Jukka Mäki ${ }^{\mathrm{b}}$, Rainer Sjöholm ${ }^{\mathrm{b}}$, and Leif Kronberg*b \\ ${ }^{a}$ Department of Chemistry, University of Turku, Vatselankatu 2, FIN-20014 Turku, Finland \\ ${ }^{b}$ Department of Organic Chemistry, Abo Akademi University, Biskopsgatan 8, \\ FIN-20500 Åbo, Finland \\ E-mail: klikakd@yahoo.co.uk, leif.kronberg@abo.fi
}

\begin{abstract}
The reaction of mucochloric acid with guanosine produces as the major product oxalyl ethenoguanosine together with a minor amount of its degradation product ethenoguanosine. Also present in trace amounts were two sets of regioisomeric $\alpha$-hydroxy chlorohydrins consisting of interconverting C-6(7) epimers for both C-7(6) stereoisomers, i.e. a total of four stereoisomers were present for each regioisomeric set. Each regioisomeric set consisted of products where a newly-formed six-membered ring was fused onto the nucleobase, one set via N-1 and N-2 of guanosine, the other via $\mathrm{N}-2$ and $\mathrm{N}-3$. The structural elucidation of the compounds was based on NMR studies $\left({ }^{1} \mathrm{H},{ }^{13} \mathrm{C}\right.$, and ${ }^{15} \mathrm{~N}$ NMR $)$ and a plausible mechanism for their creation is also presented.
\end{abstract}

Keywords: Regioisomers, stereoisomers, nucleobase adducts, $\alpha$-hydroxy chlorohydrins

\section{Introduction}

As part of our broad-based examination of nucleoside adducts ${ }^{1-5}$ for the purpose of accumulating an understanding at the unit-base level of the genotoxicity of various mutagens, both naturallyoccurring and those arising from anthropogenic activities, we herein report on additional adducts formed between mucochloric acid (1, MCA) and guanosine (see Scheme 1). MCA (1) is a chlorinated hydroxyfuranone (CHFs), a distinctive class of compounds renowned for their mutagenicity $^{6-8}$ and their ominous presence in domestic waters as a consequence of the practice of chlorination. ${ }^{6,8,9}$ The reactions of CHFs with purine bases are of interest and concern because of the damage they can inflict upon DNA and other biomolecules.

The main product formed in the reaction of MCA (1) with guanosine (2) has been identified $^{10}$ as oxalyl ethenoguanosine (3); a degradation product of 3, ethenoguanosine (4) was also identified $^{11}$ as a minor component of the reaction mixture though potentially it can arise by 
mechanisms other than via $3 .^{8,12}$ The course of these reactions and for similar CHFs are remarkable due to the sequence of seemingly improbable hydrations, substitutions, decarboxylations, and deoxalylations resulting in almost incomprehensible structural motifs given their origins. ${ }^{8}$ Though there are a number of examples of ring formation from the exocyclic nitrogen to N-1 in guanosine, including six-membered rings, ${ }^{13}$ ring formation from the exocyclic nitrogen to N-3 seems to be unknown for guanosine, at least until now, and workers have been at pains to categorically prove the preferential formation of the "linear" structures" (i.e. ring formation involving N-1). Ring size, position, and nature are all factors that need to be taken into account not only when determining the structure of DNA adducts, but also for modeling the progression of damage in such systems, thus knowledge at the unit base level is highly desirable to guide the course of studies at the biomolecular level. In any case, the reactions themselves are of immense interest per se for the myriad of pathways followed and the plethora of intriguing structures that can result. ${ }^{8}$

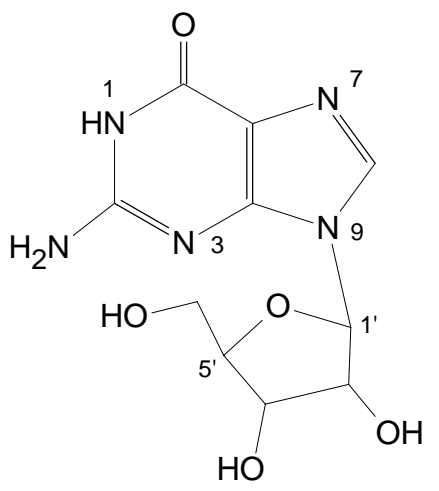

guanosine (2)

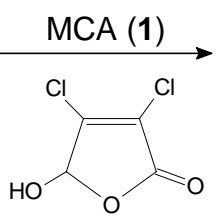

3: $\mathrm{R}=\mathrm{COCO}_{2} \mathrm{H}$, major product

4: $\mathrm{R}=\mathrm{H}$, minor degradation product of $\mathbf{3}$

Scheme 1. The reaction of MCA (1) and guanosine (2) yields mainly oxalyl ethenoguanosine (3) together with some of its degradation product 4.

\section{Results and Discussion}

The reaction of guanosine (2) with MCA (1) yielded ${ }^{10,11}$ oxalyl ethenoguanosine (3). (20-40\%) and ethenoguanosine (4) (a few percent). Also present in trace amounts $(<1 \%)$ in the reaction mixture were some products which were isolated initially as a mixture. By analytical HPLC, usually three peaks (ratio 3:2:1 in elution order) were observable for this mixture but occasionally a fourth, quite small peak, could be discerned from beneath the main first eluting peak of this set. Collection of the first peak by semi-preparative HPLC followed by standing of the fraction for some time and then re-analysis provided the first and third peaks in a similar ratio as observed for the original mixture. Similarly, collection and standing of the third peak reprovided the same result whilst collection of the middle peak yielded a mixture of the first (very 
minor) and second peaks after standing, obviously the interconversion partner of the second peak co-elutes with the first peak and only under optimal conditions could its separation be realized. The contamination of the first peak with the minor species co-eluting with it could conveniently be reduced by allowing the sample to stand; re-establishment of the equilibria led to the formation of the major species of this contaminant at the expense of the contaminant, rechromatography of the sample then allowed collection of a purer sample of the first eluting peak together with the third peak.

Thus, for structural analysis, the samples were analyzed as pairs of interconverting species. Needless to say, the NMR data for each interconverting pair were quite similar, but the sets of data for the two samples were also quite similar to each other. Minor differences between various samples of the same product were also noted (vide infra) as well as the instability of labile proton exchange rates, a phenomenon peculiar to DMSO solutions. ${ }^{3}$ Furthermore, both samples provided similar, but distinguishable, ESIMS and accurate mass analysis provided a molecular formula of $\mathrm{C}_{13} \mathrm{H}_{16} \mathrm{~N}_{5} \mathrm{O}_{7} \mathrm{Cl}$ for both. Given this, gross structural characterization was essentially straightforward and was realized by the standard application of basic 1-D and 2-D NMR techniques and consideration of chemical shifts and carbon multiplicities for all that was required was the identification of the $-\mathrm{CH}(\mathrm{OH}) \mathrm{CCl}(\mathrm{OH}) \mathrm{CH}_{2}-$ propyl segment, as esoteric as it may be. $\alpha$-Hydroxy chlorohydrins, whilst not unknown, are interesting structural motifs by virtue of their unexpected, almost counter-intuitive, stability and regioisomeric $\alpha$-hydroxy chlorohydrins (see Scheme 2) were thus postulated as the structures of these trace side-products identified as 5 (peaks 1 and 3) and 6 (peak 2).

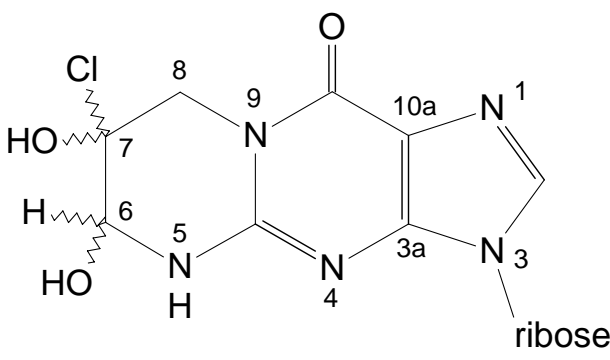

5

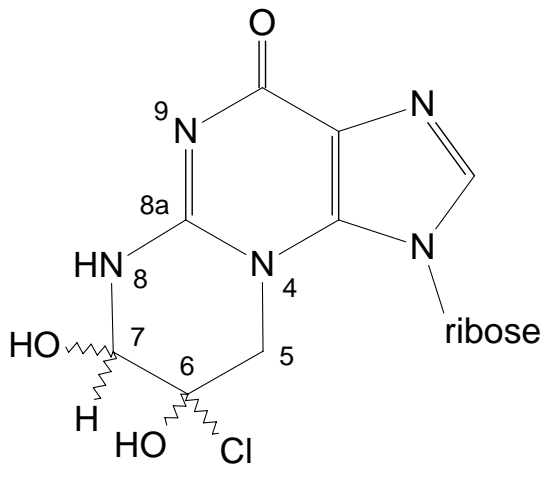

6

Scheme 2. The reaction of MCA (1) and guanosine (2) also yields the regioisomeric 5 and 6 as trace products.

Though the gross structures were quickly evident, what was not so readily apparent was the site of attachment of the propyl chain to the base, viz. was it the methylene carbon that was attached to the formerly exocyclic nitrogen or was it the hydroxy methine; and similarly was it $\mathrm{N}-3$ or N-1 of guanosine that was acting as the second nucleophile. Regioisomerism for the same skeletal structure is possible for both $\mathbf{5}$ and $\mathbf{6}$ by reverse reaction, i.e. by preferential attack of the 
endocyclic nitrogens $\mathrm{N}-1$ or $\mathrm{N}-3$, respectively, over the exocyclic nitrogen of 2 onto $\mathbf{1}$. The comparable nucleophilicity of $\mathrm{N}-1$ is notable at high $\mathrm{pH}$, but this is less certain under the conditions of this reaction however $(\mathrm{pH} 4.6)$. The distinction between the various regioisomers was hampered by an insufficient number of essential correlations, e.g. H-8s to C-10 or N-9 in 5 and $\mathrm{H}-5 \mathrm{~s}$ to $\mathrm{C}-3 \mathrm{a}$ or $\mathrm{N}-4$ in $\mathbf{6}$. Moreover, compounding this were several deceptive, four-bond correlations, e.g. H-8 to N-5 in $5(\times 2)$ and $\mathrm{H}-7$ to N-4 in $6(\times 2)$. These extended long-range correlations, i.e. over more than three bonds, in ${ }^{1} \mathrm{H}-{ }^{15} \mathrm{~N}$ HMBC spectra have been a feature frequently observed in past studies. ${ }^{15-17}$ But based on the small couplings ( $c a .1 .1 \mathrm{~Hz}$ when directly observable) and the strong NOEs between the proton of the hydroxy methine (H-6 in 5 and $\mathrm{H}-7$ in 6) and an $\mathrm{NH}$ proton (H-5 in 5 and $\mathrm{H}-8$ in 6), both sets of compounds must have the hydroxy methine carbon bound to the formerly exocyclic nitrogen of guanosine (1). This was further emphasized in the case of 6 where the coupling between one of the H-5s and N-4 was ascertained to be over two bonds based on the reasoning of Roslund $e t a .^{2}$ whereby the sign of this large coupling was discerned to be positive, in accordance with the expectation for a large coupling extending over two bonds and involving one $-\gamma$ nucleus. The product in greater abundance is expected to have the structure allotted to it, viz. 5, given the likely predominance of $\mathrm{N}-1$ attack over N-3. Substantiating this is the deshielding of all of the methylene H-5s in 6 relative to the methylene $\mathrm{H}-8 \mathrm{~s}$ in $\mathbf{5}$ due to steric compression arising from the ribose unit, though it must be conceded that the H-8s in $\mathbf{5}$ may be experiencing shielding from the carbonyl group; however, the C-5s of 6 were shielded with respect to the C-8s of 5 reinforcing the assertion. Similar effects on the ribose nuclei, however, could not be discerned. Also consistent with the assigned structures was the shielding of C-10 in both isomers of 5 relative to the C-10s in 6 due to the spatial proximity of the methylene group in the former. The UV spectra for $\mathbf{5}$ and $\mathbf{6}$ are essentially congruent and this is a surprising result for the regioisomerism assigned whereby significant differentiation would have been expected given the perturbation to the nucleobase unit.

It is clear that each structure can conceivably be present as a pair of interconverting epimers (at C-6 for $\mathbf{5}$ and C-7 for $\mathbf{6}$ ). But each epimer is not racemic as the presence of the ribose unit in addition to the asymmetric centre at C-7(6) leads to a pair of diastereomers for each epimer and thus for each regioisomer a total of four stereoisomers are likely to be present. Careful examination of the NMR spectra revealed that for a number of resonances, more than two signals, up to four in some cases, were indeed apparent, but the extent of this observation varied from sample to sample. It is altogether not unexpected that the individual diastereomers are difficult to observe as the C-6,C-7 diastereomers are almost racemic-like due to the remoteness of the ribosyl unit. Generally though, like the HPLC, the epimers were quite distinct by NMR with signal intensities in the case of only two signals for a particular resonance representative of the ratio available from HPLC.

For the major epimer of $\mathbf{5}$, the two diastereomers expected to be present are those whereby the two hydroxyls are trans to one another as this offers the optimal conditions for internal hydrogen bonding wherein a chair conformation can be adopted to permit both hydroxyls to be 
equatorially orientated. (Noting however, that the conformational mobility and geometrical flexibility of nitrogen can permit the permissive participation of a number of ring conformations in which the nitrogens are situated, or that it can lead simply to the confluence of a single, abstruse structure. ${ }^{15-18}$ ) Epimerization to provide a pair of diastereomers, whereby both hydroxyls are disposed in a cis configuration, should also be accompanied by a chair-chair conformational interchange, driven by the need to alleviate the steric hindrance of an axial hydroxyl group and the swapping of an axial chlorine for its geminal hydroxyl (assuming that in the trans case the stabilization afforded by the hydrogen bonding of two equatorial hydroxyls outweighs the axial orientation of a chlorine over a hydroxyl group). This conjecture is lent support by the observation of NOEs between H-6 and one of the H-8s for both epimers, possible only if $\mathrm{H}-6$ is axial in both cases.

Interestingly, for 6, the elution order of the major and minor epimers was reversed. Moreover, the chemical shifts of the propyl carbons, whilst maintaining similar differences between corresponding carbons of the two epimers in comparison to analogous differences in $\mathbf{5}$, were in reverse order with respect to major $v s$ minor. This suggests that the epimeric equilibrium in 6 is shifted in favor of the epimer with cis hydroxyls. This may be occurring because of hydrogen bonding from the ribose unit to 6-OH, negating the gain of having both hydroxyls equatorial at the expense of an axial chlorine. This distortion in relative energy, however, is not accompanied by a conformational change as again NOEs were observed between $\mathrm{H}-7$ and one of the $\mathrm{H}-5 \mathrm{~s}$ for both epimers.

A reaction sequence leading to the main products $\mathbf{3}$ and $\mathbf{4}$ has been proposed. ${ }^{8,10,12}$ The likely course of the reaction giving rise to the products $\mathbf{5}$ and $\mathbf{6}$ is depicted in Scheme 3. Even though the predominance of the cyclic form of $\mathbf{1}$ under the conditions of the experiment is accepted ${ }^{8,12,19}$ the course of the reaction nevertheless must occur through the open-chain form of $\mathbf{1}^{8,10,12}$ with which it is in equilibrium. ${ }^{19}$ In the open-chain form, it is the aldehyde carbon that is susceptible to attack by a nucleophile and this course is consistent with labeling experiments performed on analogous reactions. ${ }^{8,12}$ Interestingly, the chlorine in position 3 of MCA (1) is susceptible to net displacement by hydroxide ion to yield mucoxychloric acid (7), ${ }^{20}$ another potential electrophile. However, the aldehyde group in the open-chain form of $\mathbf{1}$ is a powerful electrophile and as such can be expected to be less than discriminating. Reaction with the N-2 amino group will proceed to the major products, but reaction is also possible with either $\mathrm{N}-1$ (to yield 5) or, alternatively, N-3 (to yield 6). Following immonium ion formation and elimination of hydroxide ion by the attack of $\mathrm{N}-1$ on the aldehyde carbon (intermediate A), a similar displacement of the analogous chlorine $\alpha$ to the acid functionality can feasibly also take place to yield intermediate $\mathbf{B}$. This 1,3-dienol structure can then undergo an enol $\rightarrow$ ketone shift, or more precisely, a 1,3-dienol $\rightarrow \alpha, \beta$-unsaturated ketone shift, and simultaneously release a proton to yield intermediate $\mathbf{C}$. Intermediate $\mathbf{C}$ can also conceivably arise from the direct reaction of guanosine (2) with mucoxychloric acid (7). However, this pathway is not thought to be favored on the basis of reduced yields when adenosine was reacted with $\mathbf{7}$ in comparison with $\mathbf{1}{ }^{10}$ 
In the structure of intermediate $\mathbf{C}$, there is the question of the stereochemistry about the $\mathrm{C}=\mathrm{C}$ double bond in the newly-attached sidechain and the implication it carries regarding the progress of the reaction. However, given the nature of the substituents on this double bond-two electron-withdrawing groups at one end and an electron-donating group at the other-rotation about this bond should be facile ${ }^{21}$ thus rendering the question of stereochemistry somewhat moot. The significance of the stereochemistry, or rather its ready interconversion, becomes evident after decarboxylation to yield intermediate $\mathbf{D}$. Here, only the $E$ isomer about this bond is geometrically favored to allow intramolecular attack by the $\mathrm{N}-2$ amino group onto the carbonyl. Interestingly, analogous compounds to intermediate $\mathbf{D}$ in terms of the sidechain structure have been isolated ${ }^{12}$ from the reaction of adenosine and cytidine with MCA (1) and where the same stereochemistry as depicted in $\mathbf{C}($ i.e. $Z$ ) was assigned to the double bond in question. Following intramolecular attack and cyclization incorporating an endocyclic double bond, the intermediate $\mathbf{E}$ is likely to be present as a mixture of C-6 epimers. Hydration of the double bond in intermediate $\mathbf{E}$ under mildly acidic conditions is presumably favored by the relief of strain that would result, yielding of course the products $\mathbf{5}$ as a set of all four possible stereoisomers. An analogous reaction sequence can furthermore be envisaged for the set of stereoisomers $\mathbf{6}$ starting from the condensation of N-3 with the aldehyde group in the open-chain form of $\mathbf{1}$. The presence of $\mathbf{6}$ actually discounts the notion that the formation of $\mathbf{5}$ could follow imine formation by the N2 amine (as per the main products) and then Dimroth rearrangement to intermediate $\mathbf{A}$.

The $\mathrm{pH}$ at which the reaction was conducted (4.6) results in the products being obtained as salts, but since the products appeared to be more stable when protonated, they were preferentially maintained in this state and the NMR data are thus reported for the protonated species. The site of protonation in 6 was evident by the resonance of N-9, which at $-277.9 \mathrm{ppm}$ is consistent with it being the site of protonation; ${ }^{1,3,5,23}$ upon deprotonation it obligingly resonated at $-213.1 \mathrm{ppm}$. Quite curious was the behavior of the observable N-bound H-8 proton in 6, the retention of which was dependent upon the state of protonation of the molecule, i.e. the protonation of N-9. For example, the peak half-width of $\mathrm{H}-8$ in the protonated species was uncharacteristically sharp for an $\mathrm{NH}$ proton $\left(\mathrm{v}_{1 / 2} 9 \mathrm{~Hz}\right)$, and only in the neutral form did it take on typical characteristics of an N-bound exchangeable proton $\left(v_{1 / 2}\right.$ several $\left.\mathrm{Hz}\right)$. This is the converse of what is usually observed. That this was not symptomatic of the system state was evidenced by the presence of both protonated and neutral species in the one solution, with each $\mathrm{H}-8$ signal retaining the aforementioned qualities. This quality of the H-8 signal in the protonated species could even be maintained in systems where the epimerization rate was hastened to such an extent that the rate was observable on the NMR timescale (as indicated by exchange-broadened signals and confirmed by saturation transfer from one $\mathrm{H}-10$ to the other). Even upon the addition of $\mathrm{D}_{2} \mathrm{O}$ to a DMSO- $\mathrm{d}_{6}$ solution of 6 (or 5 ), the signal of $\mathrm{H}-8(5)$ persisted for some time. This reticent behavior by $\mathrm{H}-8(5)$ in 6(5) can simply be rationalized by electron donation of $\mathrm{N}-8(5)$ to supplement the formal charge on N-9(4). 


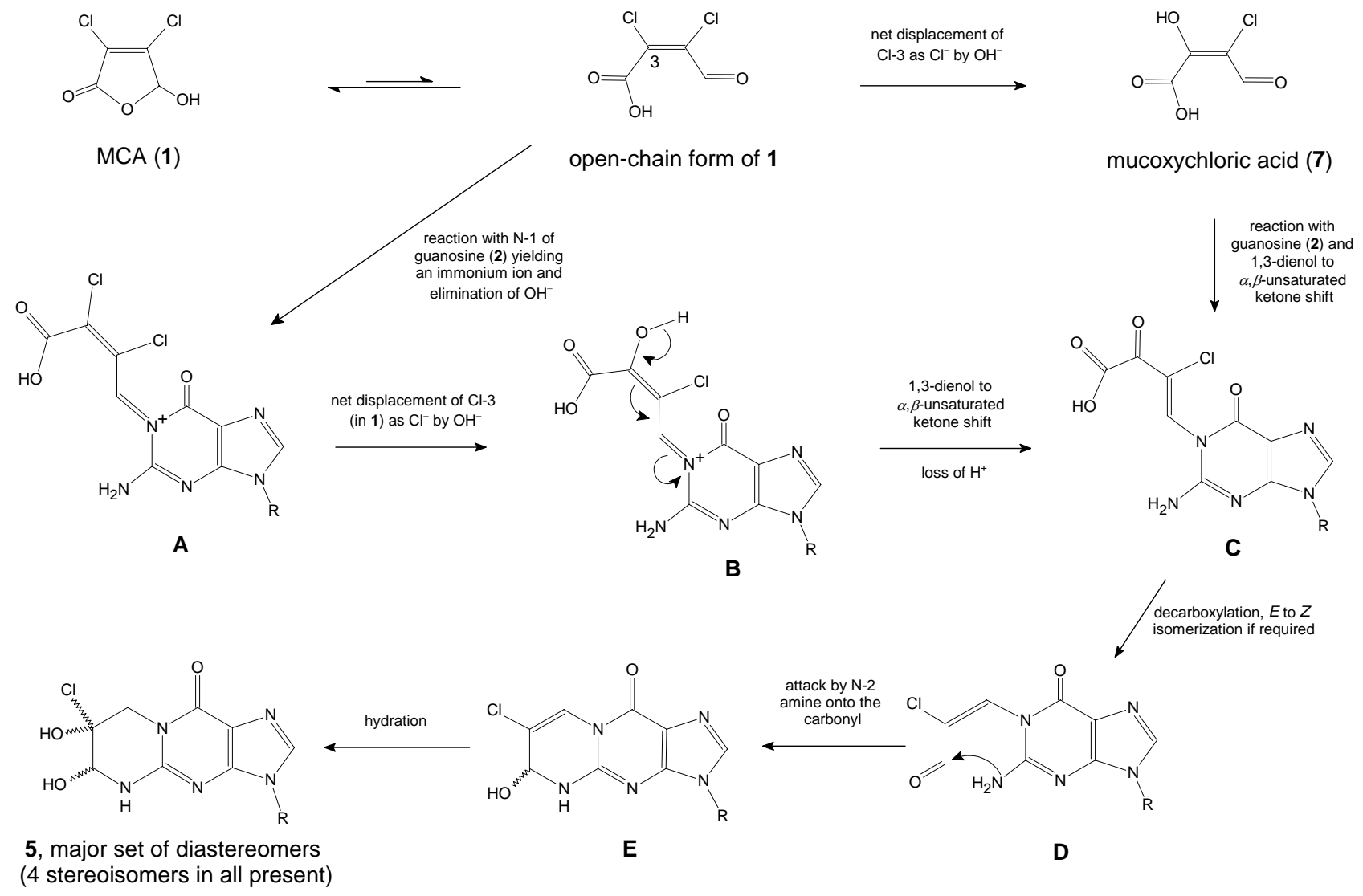

Scheme 3. The reaction sequence to yield 5 from guanosine (2) and MCA (1); an analogous reaction sequence to produce 6 is applicable from the alternate attack by N-3 of guanosine (2) onto MCA (1).

The fact that the compounds do not spontaneously degrade by dehydration or dehydrohalogenation is intriguing and the peculiar stability of these compounds is now a focus for attention. The conjecture is that the molecules adopt a conformation which is unfavorable towards such reactions, the resistance to degradation also assisted perhaps by internal hydrogen bonding. Any change which leads to conformational repositioning and/or disrupts the hydrogen bonding should therefore facilitate dehydration or dehydrohalogenation. Preliminary results by HPLC-ESIMS $^{+}$analysis revealed that the C-6(7) methoxy derivative \{obtained by incubation of 5(6) in methanol for $2-3$ days at $37^{\circ} \mathrm{C}$ and identified by an $[\mathrm{M}+\mathrm{H}]^{+}$ion of 404 amu which still lost 132 amu (i.e. underivatized ribose)\} readily lost $\mathrm{HCl}$ upon standing as implicated by a species present in solution which provided an $[\mathrm{M}+\mathrm{H}]^{+}$ion of mass $368 \mathrm{amu}$ lacking the isotopic pattern of $\mathrm{Cl}$. The di-6,7-acetyl derivative (obtained by incubating 5(6) in DMSO solution with acetic anhydride for 1 day at $37{ }^{\circ} \mathrm{C}$ and identified by an $[\mathrm{M}+\mathrm{H}]^{+}$ion of mass 474 amu, an ion which still lost underivatized ribose), also provided a species upon standing which was consistent with the loss of both acetic acid and $\mathrm{HCl}$ as indicated by an $[\mathrm{M}+\mathrm{H}]^{+}$mass of 378 amu lacking the isotopic pattern of $\mathrm{Cl}$. This interpretation must be regarded with caution, however, as 
treatment of 5(6) in DMSO with acetic acid provided both a dehydrated species $\left([\mathrm{M}+\mathrm{H}]^{+}\right.$of mass 372 amu, also seen in the reaction with acetic anhydride) and a dehydrated and dehydrochlorinated species $\left([\mathrm{M}+\mathrm{H}]^{+}\right.$of mass $\left.336 \mathrm{amu}\right)$, so disentanglement of the precise course of the reactions necessitates the acquisition of further evidence.

\section{Experimental Section}

General Procedures. Positive mode ESI were recorded on a Fisons ZABSpec-oaTOF spectrometer at a resolution of 7000 using nitrogen as both nebulizing and bath gas. A potential of $8.0 \mathrm{kV}$ was applied to the ESI needle, the temperature of the pepperpot counter electrode was $90{ }^{\circ} \mathrm{C}$, and PEG 200 was used as reference. NMR spectra were acquired at 14.1 T using a Bruker Avance NMR spectrometer equipped with a z-axis field gradient $5 \mathrm{~mm}$ inverse broadband probe operating at $600.13 \mathrm{MHz}$ for ${ }^{1} \mathrm{H}, 150.92 \mathrm{MHz}$ for ${ }^{13} \mathrm{C}$, and $60.81 \mathrm{MHz}$ for ${ }^{15} \mathrm{~N}$. 1-D and 2-D Experiments included DEPT 135, 1-D NOESY, ${ }^{1} \mathrm{H}-{ }^{13} \mathrm{C}$ and ${ }^{1} \mathrm{H}-{ }^{15} \mathrm{~N}$ HSQC,${ }^{1} \mathrm{H}-{ }^{13} \mathrm{C}$ (including standard magnitude mode, phase sensitive with decoupling, and CIGAR-HMBC; ${ }^{22}$ optimized for 4, 8, or 3-14 Hz) and ${ }^{1} \mathrm{H}-{ }^{15} \mathrm{~N} \mathrm{HMBC}$ (optimized for $8 \mathrm{~Hz}$ ), and COSY. Spectra were recorded at $25{ }^{\circ} \mathrm{C}$ in DMSO- $\mathrm{d}_{6}$ and both ${ }^{1} \mathrm{H}$ and ${ }^{13} \mathrm{C}$ chemical shifts were referenced internally to the solvent (2.50 ppm and $39.5 \mathrm{ppm}$, respectively) whilst ${ }^{15} \mathrm{~N}$ spectra were referenced externally to $90 \%$ nitromethane in $\mathrm{CD}_{3} \mathrm{NO}_{2}(0.0 \mathrm{ppm}) .{ }^{15} \mathrm{~N}$ signals were only observed indirectly whereby the $\mathrm{fl}$ dimension taken from ${ }^{1} \mathrm{H}-{ }^{15} \mathrm{~N}$ 2-D experiments was forward linear predicted to $16.4 \mathrm{~Hz} \mathrm{pt}{ }^{-1}$ (acquisition resolution $131 \mathrm{~Hz} \mathrm{pt}^{-1}$ ). Final compound purifications were conducted on a semipreparative HPLC system consisting of a Varian Model 5000 liquid chromatograph coupled to an Altex Model 153 UV-detector using a $10 \times 250 \mathrm{~mm}$ column $(8 \mu \mathrm{m}$, Hyperprep ODS, Hypersil) running a gradient of acetonitrile in water from $0-30 \%$ over the course of $25 \mathrm{~min}$ at a flow rate of $3 \mathrm{~mL} \mathrm{~min}^{-1}$. Additional details concerning general experimental procedures are available in ref 5 .

Reaction with mucochloric acid (1). CAUTION! Mucochloric acid (1) has tested positive in the Ames mutagenicity assay with Salmonella typhimurium (TA100) without metabolic activation. Due caution should therefore be exercised in the handling and disposal of samples containing this compound. MCA $(1,2.6016 \mathrm{~g}, 15.4 \mathrm{mmol})$ was reacted with guanosine $(2,1.0120 \mathrm{~g}, 3.6$ mmol) in $1 \mathrm{~L}$ of $0.5 \mathrm{M}$ aqueous phosphate buffer solution $(\mathrm{pH} 4.6)$ at $37{ }^{\circ} \mathrm{C}$ for 5 days. Unreacted 1 was then removed by extraction with diethyl ether $(4 \times 50 \mathrm{~mL})$ and the aqueous layer concentrated to a volume of $500 \mathrm{~mL}$ by rotary evaporation and stored overnight at $4{ }^{\circ} \mathrm{C}$. The crystalline salts that formed were filtered off and the mixture fractionated by column chromatography over C-18 silica eluting in gradient steps consisting of acetonitrile in water $(0,5$, 10, 15, and 20\%). Fractions of $25 \mathrm{~mL}$ were collected and fractions containing 5 and $\mathbf{6}$ were combined and concentrated to a volume of $100 \mathrm{~mL}$ and then subjected to semi-preparative HPLC to afford compounds $\mathbf{5}$ and $\mathbf{6}$ as pale yellow powders. 
For compound 5. UV-vis $\left(\mathrm{H}_{2} \mathrm{O}\right) \lambda_{\max }, 250,278 \mathrm{sh} ; \lambda_{\min }, 224 \mathrm{~nm} . \mathrm{m} / \mathrm{z}$ (ESI) $390\left(60 \%, \mathrm{MH}^{+}\right), 258$ $\left(100, \mathrm{MH}^{+}-\right.$ribosyl $\left.+\mathrm{H}\right) 240\left(3, \mathrm{MH}^{+}-\right.$ribosyl $\left.-\mathrm{H}_{2} \mathrm{O}+\mathrm{H}\right)$, calc. for $\left[\mathrm{C}_{13} \mathrm{H}_{16} \mathrm{~N}_{5} \mathrm{O}_{7} \mathrm{Cl}+\mathrm{H}\right]^{+}$: 390.0817; found: 390.0827 . NMR of major epimer: $\delta_{\mathrm{H}}\left(600.13 \mathrm{MHz}\right.$; DMSO-d $\left.{ }_{6}\right) 8.789$ (s, H-5), 8.004, (s, H-2), 7.570 (d, $\left.\mathrm{J}_{\mathrm{H} 6}=6.7 \mathrm{~Hz}, \mathrm{HO}-6\right), 6.762$ (s, HO-7), 5.705 (d, J $\mathrm{H}_{2^{\prime}}=5.8 \mathrm{~Hz}, \mathrm{H}-\mathrm{l}^{\prime}$ ), $5.548\left(\mathrm{~d}, \mathrm{~J}_{\mathrm{HO}}=6.3 \mathrm{~Hz}, \mathrm{H}-6\right), \sim 4.43\left(\mathrm{~m}, \mathrm{H}-2^{\prime}\right), \sim 4.10$ (m, H-3'), 3.90 (m, H-4'), 3.839 (d, J $\mathrm{J}_{\mathrm{H} 8 \mathrm{eq}}$ $=-11.1 \mathrm{~Hz}, \mathrm{H}-8 \mathrm{ax}), 3.706$ (d, J $\left.\mathrm{H}_{\mathrm{Hax}}=-11.3 \mathrm{~Hz}, \mathrm{H}-8 \mathrm{eq}\right), ~ 3.62$ (m, H-5'), 3.54 (m, H-5' '), HO2', HO-3', HO-6', and H-4 not observed; $\delta_{\mathrm{C}}(150.92 \mathrm{MHz}$; DMSO-d 6 ) 154.84 (C-10), 154.16 (C4a), 150.69 (C-3a), 136.28 (C-2), 118.02 (C-10a), 87.70 (C-7), 86.86 (C-1'), 85.38 (C-4'), 83.61 (C-6), $73.72\left(\mathrm{C}-2^{\prime}\right), 70.38\left(\mathrm{C}^{3} 3^{\prime}\right), 61.40\left(\mathrm{C}-5^{\prime}\right), 45.60(\mathrm{C}-8) ; \delta_{\mathrm{N}}(60.81 \mathrm{MHz}$; DMSO-d 6 ) -131.7 (N-1), -208.3 (N-3), -211.2 (N-9), -275.2 (N-5), N-4 not observed. NMR of minor epimer: $\delta_{\mathrm{H}}(600.13 \mathrm{MHz}$; DMSO-d 6 ) 8.781 (s, H-5), 7.981, (s, H-2), 7.54 (br s, HO-6), 6.389 (br s, HO7), $5.682\left(\mathrm{~d}, \mathrm{~J}_{\mathrm{H} 2^{\prime}}=6.0 \mathrm{~Hz}, \mathrm{H}-1^{\prime}\right), 5.624$ (s, H-6), 4.43 (m, H-2'), 4.10 (m, H-3'), 3.90 (m, H4'), 3.765 ( $2 \mathrm{H}, \mathrm{s}, 2 \times \mathrm{H}-8), \sim 3.62$ (m, H-5'), 3.54 (m, H-5' '), HO-2', HO-3', HO-6', and H-4 not observed; $\delta_{\mathrm{C}}\left(150.92 \mathrm{MHz}\right.$; DMSO-d $\left.\mathrm{d}_{6}\right) 154.84$ (C-10), 153.21 (C-4a), 150.69 (C-3a), 135.92 (C-2), 117.61 (C-10a), 86.70 (C-1'), 85.81 (C-7), 85.38 (C-4'), 78.39 (C-6), 73.88 (C-2'), 70.38 $\left(\mathrm{C}-3^{\prime}\right), 61.40\left(\mathrm{C}-5^{\prime}\right), 48.32(\mathrm{C}-8) ; \delta_{\mathrm{N}}\left(60.81 \mathrm{MHz} ; \mathrm{DMSO}-\mathrm{d}_{6}\right)-132.0(\mathrm{~N}-1),-208.6(\mathrm{~N}-3)$, -213.1 (N-9), -277.3 (N-5), N-4 not observed.

For compound 6. UV-vis $\left(\mathrm{H}_{2} \mathrm{O}\right) \lambda_{\max }, 250,278 \mathrm{sh} ; \lambda_{\min }, 224 \mathrm{~nm} . \mathrm{m} / \mathrm{z}$ (ESI) $390\left(87 \%, \mathrm{MH}^{+}\right), 372$ (16, $\left.\mathrm{MH}^{+}-\mathrm{H}_{2} \mathrm{O}\right), 258\left(100, \mathrm{MH}^{+}-\right.$ribosyl $\left.+\mathrm{H}\right), 240\left(11, \mathrm{MH}^{+}-\right.$ribosyl $\left.-\mathrm{H}_{2} \mathrm{O}+\mathrm{H}\right)$, calc. for $\left[\mathrm{C}_{13} \mathrm{H}_{16} \mathrm{~N}_{5} \mathrm{O}_{7} \mathrm{Cl}+\mathrm{H}\right]^{+}: 390.0817$; found: 390.0822 . NMR of major epimer: $\delta_{\mathrm{H}}(600.13 \mathrm{MHz}$; DMSO-d $\left.{ }_{6}\right) 8.779$ (s, H-8), 7.966, (s, H-2), 7.064 (s, HO-6), 6.558 (d, $\left.J_{\mathrm{H} 7}=7.6 \mathrm{~Hz}, \mathrm{HO}-7\right), 5.674$ $\left(\mathrm{d}, J_{\mathrm{H}^{\prime}}=5.8 \mathrm{~Hz}, \mathrm{H}-1^{\prime}\right), 5.396$ (br s, HO-2', HO-3', or HO-6'), 5.155 (d, $\left.J_{\mathrm{HO} 7}=6.9 \mathrm{~Hz}, \mathrm{H}-7\right)$, 5.133 (br s, HO-2', HO-3', or HO-6'), 5.011 (br s, HO-2', HO-3', or HO-6'), 4.533 (d, $J_{\mathrm{H} 5 \mathrm{ax}}=$ $-11.0 \mathrm{~Hz}, \mathrm{H}-5 \mathrm{eq}), \sim 4.38$ (m, H-2'), 4.09 (m, H-3'), 3.929 (d, $\left.J_{\mathrm{H} 5 \mathrm{eq}}=-10.8 \mathrm{~Hz}, \mathrm{H}-5 \mathrm{ax}\right), \sim 3.89$ (m, H-4'), 3.62 (m, H-5'), 3.53 (m, H-5' $)$, H-9 not observed; $\delta_{\mathrm{C}}\left(150.92 \mathrm{MHz}\right.$; DMSO-d $\left.\mathrm{d}_{6}\right)$ 155.32 (C-10), 153.95 (C-8a), 150.61 (C-3a), 135.81 (C-2), 117.43 (C-10a), 89.27 (C-6), 86.48 (C-1'), $85.32\left(\mathrm{C}-4^{\prime}\right), 79.36(\mathrm{C}-7), 73.90\left(\mathrm{C}-2^{\prime}\right), 70.33\left(\mathrm{C}-3^{\prime}\right), 61.33\left(\mathrm{C}-5^{\prime}\right), 45.41(\mathrm{C}-8) ; \delta_{\mathrm{N}}(60.81$ MHz; DMSO-d 6 ) -139.6 (N-1), -208.4 (N-3), -216.8 (N-4), -277.9 (N-9), -281.2 (N-8). NMR of minor epimer: $\delta_{\mathrm{H}}\left(600.13 \mathrm{MHz}\right.$; DMSO-d $\left.{ }_{6}\right) 8.814$ (s, H-8), 7.970, (s, H-2), 7.461 (s, HO-6), $6.742\left(\mathrm{~d}, J_{\mathrm{H} 7}=7.0 \mathrm{~Hz}, \mathrm{HO}-7\right), 5.683\left(\mathrm{~d}, J_{\mathrm{H}^{\prime}}=5.7 \mathrm{~Hz}, \mathrm{H}-1^{\prime}\right), 5.396$ (br s, HO-2', HO-3', or HO$6^{\prime}$ ), 4.963 (d, $J_{\mathrm{HO} 7}=6.3 \mathrm{~Hz}, \mathrm{H}-7$ ), 5.133 (br s, HO-2', HO-3', or HO-6'), 5.011 (br s, HO-2', HO-3', or HO-6'), 4.610 (d, $\left.J_{\mathrm{H} 5 \mathrm{ax}}=-10.8 \mathrm{~Hz}, \mathrm{H}-5 \mathrm{eq}\right), 4.38$ (m, H-2'), 4.149 (d, $J_{\mathrm{H} 5 \mathrm{eq}}=-10.8$ Hz, H-5ax), 4.09 (m, H-3'), 3.89 (m, H-4'), 3.62 (m, H-5'), 3.53 (m, H-5' ), H-9 not observed; $\delta_{\mathrm{C}}\left(150.92 \mathrm{MHz}\right.$; DMSO-d $\left.{ }_{6}\right) 155.63$ (C-10), 154.81 (C-8a), 150.64 (C-3a), 135.95 (C2), 117.56 (C-10a), 92.46 (C-6), 86.63 (C-1'), 85.32 (C-4'), 84.38 (C-7), 73.80 (C-2'), 70.33 (C$\left.3^{\prime}\right), 61.33\left(\mathrm{C}-5^{\prime}\right), 43.22(\mathrm{C}-8) ; \delta_{\mathrm{N}}(60.81 \mathrm{MHz}$; DMSO-d 6 ) -139.6 (N-1), -208.4 (N-3), -212.8 $(\mathrm{N}-4),-277.9(\mathrm{~N}-9),-280.2(\mathrm{~N}-8)$. 


\section{Acknowledgements}

We are grateful to Mr Markku Reunanen for the recording of accurate mass spectra.

\section{References}

1. Mäki, J.; Klika, K. D.; Sjöholm, R.; Kronberg, L. J. Chem. Soc., Perkin Trans. 1 2001, 1216.

2. Roslund, M. U.; Virta, P.; Klika, K. D. Org. Lett. 2004, 6, 2673.

3. Mäki, J.; Tähtinen, P.; Kronberg, L.; Klika, K. D. J. Phys. Org. Chem. 2005, 18, 240.

4. Pawłowicz, A. J.; Munter, T.; Klika, K. D.; Kronberg, L. Bioorg. Chem. 2006, 34, 39.

5. Virta, P.; Koch, A.; Roslund, M. U.; Mattjus, P.; Kleinpeter, E.; Kronberg, L.; Sjöholm, R.; Klika, K. D. Org. Biomol. Chem. 2005, 3, 2924.

6. Hemming, J.; Holmbom, B.; Reunanen, M.; Kronberg, L. Chemosphere 1986, 15, 549.

7. Kronberg, L.; Vartiainen, T. Mutat. Res. 1988, 206, 177.

8. Mäki, J. Ph.D. thesis, Åbo Akademi University, 2003, and references cited therein.

9. Smeds, A.; Vartiainen, T.; Mäki-Paakkanen, J.; Kronberg, L. Environ. Sci. Technol. 1997, $31,1033$.

10. Mäki, J.; Sjöholm, R.; Kronberg, L. J. Chem. Soc., Perkin Trans. 1 1999, 2923.

11. Kronberg, L.; Sjöholm, R.; Karlsson, S. Chem. Res. Toxicol. 1992, 5, 852.

12. Kronberg, L.; Asplund, D.; Mäki, J.; Sjöholm, R. Chem. Res. Toxicol. 1996, 9, 1257.

13. Moschel, R. C.; Leonard, N. J. J. Org. Chem. 1976, 41, 294.

14. Czarnik, A. W.; Leonard, N. J. J. Org. Chem. 1980, 45, 3514.

15. Rosling, A.; Klika, K.; Fülöp, F.; Sillanpää, R.; Mattinen, J. Heterocycles 1999, 51, 2575.

16. Rosling, A.; Klika, K. D.; Fülöp, F.; Sillanpää, R.; Mattinen, J. Acta Chem. Scand. 1999, 53, 103.

17. Rosling, A.; Hotokka, M.; Klika, K. D.; Fülöp, F.; Sillanpää, R.; Mattinen, J. Acta Chem. Scand. 1999, 53, 213.

18. Tähtinen, P.; Bagno, A.; Klika, K. D.; Pihlaja, K. J. Am. Chem. Soc. 2003, 125, 4609.

19. Kim, D. H.; Harp, D. N. Chem. Ind. 1965, 183-184.

20. Wasserman, H. H.; Precopio, F. M. J. Am. Chem. Soc. 1952, 74, 326.

21. Klika, K. D.; Imrich, J.; Danihel, I.; Böhm, S.; Kristian, P.; Hamul'aková, S.; Pihlaja, K.; Koch, A.; Kleinpeter, E. Magn. Reson. Chem. 2005, 43, 380 and references therein.

22. Hadden, C. E.; Martin, G. E.; Krishnamurthy, V. V. Magn. Reson. Chem. 2000, 38, 143.

23. Berger, S.; Braun, S.; Kalinowski, H. O. NMR Spectroscopy of the Non-Metallic Elements, Wiley, Chichester, 1997, English Edition, Ch. 4. 